\title{
A TERRA DOS MENINOS PELADOS E O ESTADO DE EXCEÇÃO: UM PROJETO ESTÉTICO GRACILIÂNICO
}

Resumo: Graciliano Ramos, autor cânone da literatura brasileira, é mais reconhecido por suas produções literárias adultas, como Vidas Secas, São Bernardo, Memórias do Cárcere. Contudo, Ramos também deixou para seus leitores, narrativas destinadas ao público infantil, como Histórias de Alexandre, A terra dos meninos pelados, Pequena História da República, e os contos "Minsk" e "Luciana". Refletindo sobre como a crítica vem privilegiando algumas obras de Graciliano Ramos em suas análises e deixando à margem, principalmente, as narrativas infantis, resolvemos ponderar $e$ pensar o projeto estético graciliânico $e$ como esse perpassa necessariamente todas as suas produções literárias e também como a análise de um Estado de exceção ultrapassa o conceito clássico exposto por alguns teóricos, como Giorgio Agamben.

Palavras-Chave: A terra dos meninos pelados. Projeto estético. Estado de exceção. Literatura brasileira. Graciliano Ramos

\section{Lilliân Alves BORGES ${ }^{1}$}

Universidade Federal de Uberlândia - UFU
Abstract: Graciliano Ramos, canon author of Brazilian literature, is more recognized for his adult literary productions, such as "Vidas Secas", "São Bernardo", "Memórias do Cárcere". However, Ramos also left to his readers, narratives aimed at children's audiences, such as "Histórias de Alexandre", "A terra dos meninos pelados", "Pequena História da República", and the short stories "Minsk" and "Luciana." Reflecting on how criticism has favored some of Graciliano Ramos' works in his analysis and leaving aside, especially, children's narratives, we have decided to ponder and think about the Graciliano Ramos aesthetic project and how this necessarily pervades all his literary productions and also as the analysis of an Exception State goes beyond the classical concept put forward by some theorists, such as Giorgio Agamben.

Keywords: A terra dos meninos pelados. Aesthetic project. Exception State. Brazilian Literature. Graciliano Ramos.

\footnotetext{
${ }^{1}$ Doutoranda em Estudos Literários na Universidade Federal de Uberlândia - UFU. Mestre em Estudos Literários pela Universidade Federal de Uberlândia - UFU. Especialista pela Universidade Federal do Triângulo Mineiro - UFTM (2009).
} 
- O que houve?

- Ele era meu amigo, estivemos presos juntos.

Meu Deus! Calei-me, como um velório, para ouvir.

- Eles nos tiram tudo. Não de uma vez, mas pouco a pouco. Até a miséria, o desespero, a loucura final.

Seu clima era o de Histórias de Alexandre, pronto e a sair. Ou talvez, mais ainda, o de Infância, que estava escrevendo. Mas já não estaria pensando em Memórias do Cárcere? (RAMOS, 2011, p. 88)

\section{Introdução}

Giorgio Agamben em seu livro Estado de exceção (2004), apresenta-nos algumas reflexões, as quais nos ajudam a compreender o que é e como é constituído o Estado de exceção, conforme podemos verificar na citação a seguir:

as medidas excepcionais encontram-se na situação paradoxal de medidas jurídicas que não podem ser compreendidas no plano do direito, e o estado de exceção apresenta-se como a forma legal daquilo que não pode ter forma legal. Por outro lado, se a exceção ao dispositivo original graças ao qual o direito se refere a vida e a inclui em si por meio de sua própria suspensão, uma teoria do estado de exceção e, então, condição preliminar para se definir a relação que liga e, ao mesmo tempo, abandona o vivente ao direito. (AGAMBEN, 2004, p.13-14, grifo nosso)

Refletindo sobre essa condição que "abandona o vivente ao direito", podemos fazer referência a diversos personagens de Graciliano Ramos em suas diferentes narrativas, não ficando somente restritos à sua chamada obra adulta, ou seja, aquela destinada ao público adulto.

Enfatizamos essa distinção feita pela crítica entre literatura para adultos $\mathrm{x}$ literatura infantil e juvenil do autor, pois muito tem sido escrito acerca das obras de Graciliano Ramos dirigidas ao público adulto, deixando a obra destinada às crianças à margem. É o que constatamos no artigo intitulado "Graciliano na Terra dos meninos pelados", de Ricardo Ramos filho: "uma das questões que mais chamam a atenção quando abordamos a obra de Graciliano Ramos está na desproporção com que é estudada. (RAMOS FILHO, 2017, p.284). Essa desproporção acerca da produção crítica sobre a literatura infantil e juvenil escrita por Graciliano Ramos pode ter sido impulsionada pelo modo como a maioria dos críticos analisam de forma negativa a referida literatura:

Como nessa fase nem mesmo a narrativa mais longa e mais ambiciosa, "Alexandre", deve ter-lhe inspirado contorno à linha de pesquisa 
anterior. Continuar trabalhando a linguagem de escritor, perseguindo se possível crescente exigência, para o entendimento do mundo. Foi quando se entregou à memorialística. Caminhar nesse sentido significava, além do mais, uma retomada da obra anterior, na medida em que iria aprofundar resíduos de experiência pessoal que haviam impregnado, por exemplo, Angústia. Daí para a frente, Graciliano se concentraria no trabalho de produzir Infância e Memórias do cárcere postumamente. (MOURÃO, 2011, p. 204)

O trecho supracitado se refere ao posfácio escrito por Rui Mourão para a edição de 2011 de Alexandre e outros heróis. Nessa compilação estão as narrativas: Histórias de Alexandre, A terra dos meninos pelados e Pequena história da República. Como facilmente observável, Rui Mourão acredita que essas narrativas não exigiram tanta atenção por parte de Graciliano Ramos, como se as obras infantis não representassem o projeto estético percorrido pelo autor e muito menos projetasse a sua ideologia, uma ideologia marcada por princípios comunistas e que buscava a igualdade social.

Assim, pensando na adjetivação da literatura graciliânica, especificamente obra adulta x obra infantil, que neste texto, pretendemos demonstrar que o projeto literário de Graciliano Ramos é contínuo e perpassa toda sua produção literária, havendo, portanto, um paulatino diálogo entre suas obras: "mesmo sendo um conto infantil, A terra dos meninos pelados traz essa marca de Graciliano impressa em suas páginas. Raimundo pode ombrear-se com João Valério, Luís da Silva, Fabiano, sinha Vitória, Madalena e Paulo Honório”. (RAMOS FILHO, 2017, p.283, grifo nosso). Além disso, realizaremos uma leitura da narrativa A terra dos meninos pelados e demonstraremos como o personagemprotagonista Raimundo lida com a deflagração de um Estado de exceção, Estado de exceção esse que está presente também nas outras narrativas graciliânicas.

\section{A terra dos meninos pelados}

Graciliano Ramos escreve a narrativa A terra dos meninos pelados logo após a sua saída da prisão em $1937^{2}$ com o objetivo de participar do concurso da Comissão Nacional de Literatura Infantil (CNLI). O livro acaba premiado com o terceiro lugar no concurso.

\footnotetext{
${ }^{2}$ Graciliano Ramos ficou preso durante dez meses e dez dias durante a Ditatura Vargas. A sua prisão não foi embasada por nenhuma acusação formal, como foi verificado por nós no capítulo "Prisão: 'motivo sempre há, motivo se arranja", de nossa dissertação intitulada "Nos rastros do sujeito: espacialidades, subjetivação, dessubjetivação em Memórias do Cárcere'”. (BORGES, 2017)
} 
A narrativa conta a história do personagem Raimundo, um menino que é careca e possui um olho azul e o outro preto. Tendo em vista essa sua diferença física, Raimundo sofre o que hoje podemos denominar bullying ${ }^{3}$, ou seja, o protagonista da narrativa é vilipendiado pelas outras crianças, as quais, de certa forma, não acham Raimundo bonito ou não gostam dele em função de sua diferença física.

Não suportando mais as críticas com sua aparência, Raimundo cria para si mesmo a terra de Tatipirun:

Um dia em que ele preparava com a areia molhada, a serra de Taquaritu e o rio das Setes Cabeças, ouviu os gritos dos meninos escondidos por detrás das árvores e sentiu um baque no coração.

- Quem raspou a cabeça dele? Perguntou o moleque do tabuleiro.

- Como botaram os olhos de duas criaturas numa cara? Berrou o italianinho da esquina.

- Era melhor que me deixassem quieto, disse Raimundo baixinho.

Encolheu-se e fechou o olho direito. Em seguida foi fechando o olho esquerdo, não enxergou mais a rua. As vozes dos moleques desapareceram, só se ouvia a cantiga das cigarras. Afinal as cigarras se calaram.

Raimundo levantou-se, entrou em casa, atravessou o quintal e ganhou o morro. Aí começaram a surgir as coisas estranhas que há na terra de Tatipirun, coisas que ele tinha adivinhado, mas nunca tinha visto. (RAMOS, 1977, p.100)

Fizemos o uso dessa citação mais extensa para mostrar o momento exato em que o personagem Raimundo começa a criar a terra de Tatipirun, uma terra em que todos os meninos e meninas são iguais a ele e que ninguém é ridicularizado por ser diferente. Podemos afirmar que o país de Tatipirun, assim como o país das Maravilhas de Alice ou a terra de $\mathrm{Oz}$ de Dorothy, são os espaços topofílicos ${ }^{4}$ para os seus protagonistas. Em outras palavras, são espaços geradores de bem-estar, harmonia, equilíbrio. Na relação entre os personagens e esses espaços há a produção de sentimentos eufóricos, de prazer.

É nesse espaço topofílico, então, que o personagem Raimundo se refugia para fugir do Estado de exceção, no qual está inserido em sua realidade. Relevante apontar que a necessidade por um espaço topofílico, guardadas as suas respectivas diferenças, é uma

\footnotetext{
${ }^{3}$ Palavra inglesa de origem latina cujo correspondente em português é BULINAGEM. Ambas têm origem no verbo latino "bullinare" que em português significa bulinar, com a acepção de: mexer com, incomodar, intimidar, assediar. http://www.dicionarioinformal.com.br/significado/bullying/3728/.

${ }^{4} \mathrm{O}$ termo topofilia foi estudado por Gaston Bachelard em seu livro A poética do Espaço (2008): "No presente livro, nosso campo de exame tem a vantagem de ser bem delimitado. Isso porque pretendemos examinar imagens bem simples, as imagens do espaço feliz. Nessa perspectiva, nossas investigações mereceriam o nome de topofilia. (BACHELARD, 2008, p. 19, grifos do autor)
} 
constante em grande parte da obra de Graciliano Ramos, como podemos observar em Histórias de Alexandre, Vidas Secas, Caetés, Angústia e também no conto "Luciana". Discorreremos posteriormente mais detalhadamente sobre essas semelhanças no projeto estético literário do autor.

\section{Estado de Exceção na obra graciliânica}

Conforme já discorremos anteriormente neste texto, a maior parte da crítica literária acerca das narrativas de Graciliano Ramos está direcionada a sua obra adulta, sendo que a maioria dos críticos consideram que a verificação da ideologia do autor estaria presente somente nessas narrativas. Em vista disso, perguntamo-nos: será que, no momento em que Graciliano Ramos começou a escrever seus livros destinados ao público infantil, o seu projeto literário foi pausado? Será que suas narrativas infantis não fazem parte de seu projeto estético? Não conseguimos depreender a postura crítica e ideológica do escritor em suas narrativas infantis? E, refletindo sobre a temática inserida em suas obras infantis, podemos nos remeter ao desvelamento de um pensamento comunista e da descrição de um Estado de exceção nas relações entre os personagens e o mundo em que estão inseridos?

De acordo com Ricardo Ramos filho:

A terra dos meninos pelados foi escrito logo após o autor alagoano ter sido solto. Desse modo, uma das vozes que pode ser considerada e ouvida desde o início é aquela que insere o escritor em uma experiência recém-vivida de exclusão da sociedade por ter, pretensamente, opiniões políticas diferentes daquelas autorizadas pela ditadura. De certa forma, a cabeça pelada do menino Raimundo faz dele alguém muito próximo do Graciliano detento na Colônia Correcional de Ilha Grande, submetido a um ritual de raspagem de cabelos, humilhante, doloroso, violência cometida na friagem da noite". (RAMOS FILHO, 2017, p. 297)

Raimundo, o protagonista da narrativa, assim como o autor Graciliano Ramos, veem-se excluídos da sociedade por serem diferentes.

O Graciliano de Memórias do Cárcere é preso possivelmente por ter ideias e ideais que contrariam a norma vigente da Ditadura Varguista. O Estado de exceção é deflagrado no Brasil no momento em que o país, estando em uma crise política, se vê na imersão de uma tomada do poder por Getúlio Vargas, presidente do período, o qual, na tentativa de restabelecer a ordem e tentar afastar "o perigo comunista", instaura um Estado de exceção em quem todos e tudo aquilo que possa infringir as regras é excluído, 
segregado e preso. É, nesse momento, que Graciliano se percebe como um sujeito que possui os direitos individuais suspendidos em prol de um “bem comum”. Sua ideologia, seus livros, enfim, seu modo de posicionar-se perante os acontecimentos políticos do Brasil, fazem dele um "inimigo do país", e por ser esse "inimigo" é encarcerado. No cárcere, percebe que, aos poucos, tudo aquilo que ele é, ou seja, toda a sua identidade é subtraída na tentativa de uma nova construção identitária. Essa nova identidade é permeada por uma ideologia do período ditatorial varguista e é paulatinamente construída e inserida no convívio de todos aqueles que estão presos e também em "liberdade".

Ricardo Ramos, ao retratar uma conversa que teve com seu pai Graciliano Ramos no livro Graciliano Ramos: retrato fragmentado (2011), demonstra a constatação que o pai obteve do período de encarceramento: "Eles nos tiram tudo. Não de uma vez, mas pouco a pouco. Até a miséria, o desespero, a loucura final”. O Estado de exceção retira tudo do sujeito, em função da norma estabelecida, de um falso equilíbrio e de uma justiça igualitária.

O Graciliano de Memórias do Cárcere, por ser diferente do que espera o Estado de Exceção instaurado por Getúlio Vargas, acaba sendo preso, tem seus objetos apreendidos, o cabelo raspado, a roupa trocada e até mesmo perde o seu nome, o qual é substituído por um número na Colônia Correcional de Dois Rios. Já Raimundo em A terra dos meninos pelados, uma criança diferente fisicamente percebe que o seu mundo real está inserido, também, dentro, de certo modo, de um Estado de exceção. Ser careca, ter um olho de cada cor não é a norma, o que desencadeia a sua segregação. Sua diferença incomoda, gera discussão e por isso Raimundo sentindo-se excluído pelas outras crianças, acaba se isolando. Relevante ressaltar que alguns críticos afirmam que a construção física do personagem Raimundo é uma referência direta ao período em que Graciliano Ramos ficou preso, fazendo assim uma crítica à Ditadura Vargas.

Raimundo usa a imaginação para criar o país de Tatipirun, um país em que sua diferença é aceita, onde "todos os caminhos são certos" (RAMOS, 1977, p. 102) e todos os meninos são carecas e possuem um olho azul e o outro preto.

Por meio do modo como Graciliano Ramos constrói sua narrativa é possível percebemos que a sua preocupação com uma sociedade igualitária está presente em $A$ terra dos meninos pelados, mas de uma forma lúdica, em que a imaginação, a fantasia é a propulsora de todos os acontecimentos. É no mundo da fantasia que o personagem Raimundo consegue ter o mundo que sempre sonhou: "Todos ali estavam descalços e 
cobertos de panos brancos, azuis, amarelos, verdes, roxos, cor das nuvens do céu e cor do fundo do mar inteiramente iguais às teias que as aranhas vermelhas fabricavam" (RAMOS, 1977, p.104).

No mundo de Tatipirun de Raimundo, todas as crianças são iguais, vestem as mesmas roupas, não possuem sapatos e não existem casas. Todos dormem no chão cobertos pelas vitrolas. Refletindo sobre essa possível inserção da ideologia comunista ${ }^{5}$ de Graciliano Ramos em suas obras, observamos como o país imaginário de Raimundo é um espaço utópico ${ }^{6}$, um espaço fora da realidade, mas que representa anseios materiais e físicos bem realistas, os quais fazem parte do mundo real de Raimundo.

Em diversos momentos da produção literária de Graciliano Ramos, é possível observar que seus personagens buscam por um espaço utópico em que possam ser felizes, conforme mesmo elucida Antonio Candido em seu ensaio Ficção e Confissão (2012): “a literatura é o seu protesto, o modo de manifestar a reação contra o mundo das normas constritoras. Como em quase todo artista, a fuga da situação por meio da criação mental é o seu jeito peculiar de inserir-se nele, de nele definir um lugar" (CANDIDO, 2012, p. 88). Como exemplo dessa literatura de resistência, podemos trazer a lume também Histórias de Alexandre (1945), narrativa infantil composta por quinze contos que conta a história do personagem Alexandre, um sertanejo que vive a contar histórias de um passado permeado com acontecimentos fantásticos e, mais do que isso, um passado em que ele era um sujeito importante na sociedade, e não apenas um sujeito à margem como é em sua realidade prosaica. Além de Histórias de Alexandre, no conto "Luciana", Graciliano Ramos desvela o universo infantil, apresentando uma menina que em diversos momentos de sua vida, vislumbra um mundo diferente da realidade em que vive:

Luciana avizinhou-se do sofá nas pontas dos pés, imitando as senhoras que usam sapatos de tacão alto. Gostava desse exercício, convidava a irmã para brincar de moça. Encolhida e pálida, Maria Júlia cambaleava

\footnotetext{
${ }^{5}$ Apesar de ter demonstrado possuir uma ideologia que perpassava pelos ideais do Partido Comunista, Graciliano Ramos somente ingressa no partido no ano de 1945. Como representante do partido viaja para a Tchecoslováquia e à União Soviética em 1952. O livro Viagem publicado em 1954 é o relato dessa viagem.

${ }^{6}$ Quando nos remetemos a concepção de espaço utópico, estamos nos referindo a conceituação proposta por Michel Foucault em seu texto "Outros espaços" (1967) Há, inicialmente. as utopias. As utopias são os posicionamentos sem lugar real. São posicionamentos que mantêm com o espaço real da sociedade uma relação geral de analogia direta ou inversa. É a própria sociedade aperfeiçoada ou é o inverso da sociedade, mas, de qualquer forma, essas utopias são espaços que fundamentalmente são essencialmente irreais. (FOUCAULT, 2006, p.415)
} 
- e Luciana se arranjava só: prendia cordões numa caixa vazia, que se transformava em bolsa, com um pedaço de pau armava-se de sombrinha e lá ia remedando um pássaro que se dispõe a voar, inclinada para a frente, os calcanhares apoiados em saltos enorme e imaginários. Assim aparelhada, chamava-se d. Henriqueta de Boa-Vista. (RAMOS, 2013, p. 54)

Apresentando a mesma necessidade de um espaço utópico, na obra Caetés, Graciliano Ramos, apresenta-nos o personagem João Valério, um sujeito que vivia a fantasiar uma outra vida para si mesmo. Uma vida permeada por glória, reconhecimento, abundância financeira. Vejamos abaixo uma passagem da narrativa:

Talvez, com algum trabalho, conseguisse completar para ela um soneto que andei compondo aos quinze anos e que teria saído bom se não emperrasse no fim. Depois obteria umas entrevistas à noite, à janela, e, conversa puxa conversa, pregava-lhe, ao cabo de uma semana, meia dúzia de beijos. Ficávamos noivos, casávamos, D. Engrácia morria. Imaginei-me proprietário, vendendo tudo, arredondando aí uns quinhentos contos, indo viver no Rio de Janeiro com Marta, entre romances franceses, papéis de música e flores de parafina. Onde iria morar? Na Tijuca, em Santa Teresa, ou em Copacabana, um dos bairros que vi nos jornais. Eu seria um marido exemplar e Marta uma companheira deliciosa, dessas fabricadas por poetas solteiros. Atribuílhes os filhos destinados a Luísa, quatro diabretes fortes e espertos. Suprimi radicalmente Nicolau Varejão, ser inútil.

Achava-me em pleno sonho, num camarote do Municipal, quando Adrião se abeirou da carteira. (RAMOS, 1977, p. 37)

O mesmo sonho, ou melhor, um devaneio semelhante ocorre em Angústia quando

Luís da Silva pensa em como seria sua vida caso fosse um sujeito bem-sucedido:

- Meus parabéns, seu Silva. O senhor escreveu uma obra excelente Está aqui a opinião dos críticos.

- Muito obrigado, doutor.

Abro a torneira, molho os pés. Às vezes passo uma semana compondo esse livro que vai ter grande êxito e acaba traduzido em línguas distantes. Mas isto me enerva. Ando no mundo da lua. (RAMOS, 2014, p.163)

O que Raimundo, Luciana, João Valério, Luís da Silva possuem em comum? Todos vivem, de certa forma, em um Estado de exceção. Conforme elucida Agamben: “por outro lado, se a exceção é o dispositivo original graças ao qual o direito se refere a vida e a inclui em si por meio de sua própria suspensão, uma teoria do estado de exceção e, então, condição preliminar para se definir a relação que liga e, ao mesmo tempo, abandona o vivente ao direito" (AGAMBEN, 2004, p.12). Em outras palavras, todos esses personagens de Graciliano Ramos vivem um determinado momento de suas vidas em que 
seus direitos foram suprimidos, logo são humilhados, excluídos, são sujeitos que vivem à margem da sociedade.

Importante destacar que podemos considerar os personagens Luciana e Raimundo como duplamente excluídos sociais, primeiramente porque são crianças e assim sendo, partindo do modo como a criança é concebida em nossa sociedade, eles não possuem o direito à voz, são apartados do convívio dos adultos; e segundo porque são "diferentes". Luciana é uma criança que gosta de inventar, criar situações mirabolantes, fantasiosas e por isso está sempre "levando uma bronca" de sua mãe, além de sempre tentar disputar a atenção dos adultos e fazer parte do convívio deles. Em contrapartida, Raimundo é o estigma da diferença. Sua diferença física incomoda e representa tudo aquilo que não se pode ser em uma sociedade, uma sociedade a qual preza por normas e convenções sociais, em que todo mundo deve ser e se comportar de determinada maneira.

Pelo exposto até o momento, podemos constatar que o escritor Graciliano Ramos não pausa seu projeto literário quando se dedica ao público infantil e sim demonstra por meio de suas produções infantis como é possível escrever para crianças não infantilizando a narrativa, nem facilitando ou até mesmo excluindo a criança do processo de construção de sentido. Para isso, Graciliano Ramos utiliza-se do fantástico para buscar uma identificação entre a criança leitora de suas narrativas com os protagonistas e suas aventuras. Assim, acreditamos que as crianças leitoras de suas obras conseguem se identificar com a temática e conseguem produzir sentidos a partir da leitura ao se tornarem o centro da narrativa. Além disso, as crianças conseguem obter voz, sair do Estado de exceção em que a sociedade a colocou e assim serem agentes de suas próprias vida.

Outro aspecto por nós observado trata-se do fato de que é possível constatar que a postura crítica e ideológica de Graciliano Ramos perpassa tanto sua produção adulta quanto infantil, porém, ela é realizada de forma diferente, uma vez que na literatura infantil ocorre por meio da irrupção do elemento fantástico. Dessa maneira, conforme atesta Candido (2012), Graciliano Ramos "vê o mundo através dos seus problemas pessoais; sente necessidade de lhe dar contorno e projeta nos personagens a sua substância, deformada pela arte" (CANDIDO, 2012, p.89). Consequentemente, entendemos que Ramos não deixa à margem suas concepções ideológicas ao escrever para as crianças, tanto que notamos a propagação de sua ideologia tanto em Histórias de Alexandre quanto em A terra dos meninos pelados, pois para Ramos, "a literatura está 
inseparavelmente ligada à vida, que deve retratar a vida social e receber suas influências no sentido da marcha para a frente" (FACÓ, 2014, p.161).

Retornando especificamente para a análise da narrativa A terra dos meninos pelados, observamos uma criança presa, de certa forma, aos ditames sociais, em que ser diferente não é aceito; e, vendo-se obrigado a tentar superar a opressão vivida, o protagonista Raimundo cria o mundo maravilhoso do país de Tatipirun. Tatipirun é o paraíso, onde todos são iguais, possuem os mesmos bem materiais e a tecnologia está a serviço de todos, a natureza não é explorada e sim usada para o bem-estar das crianças que moram lá. A tecnologia também é acessível a todos, como o rio que se abre e fecha para todos os meninos e meninas de Tatipirun atravessarem para o outro lado da margem do rio: "O rio se fechou de repente e a multidão passou por ele num instante. Depois as margens se afastaram, a água tornou a aparecer. - Que rio interessante! Exclamou Raimundo. Deve ter um maquinismo por dentro" (RAMOS, 1977, p. 107).

Ademais, tudo em Tatipirun é agradável, até mesmo o tempo, já que não faz nem frio e nem calor, como podemos notar na passagem:

- Isto é agradável, murmurou Raimundo. Tudo alegre, cheio de saúde... A propósito, ninguém adoece em Tatipirun, não é verdade?

- Adoece como?

- Julgo que vocês não vão ao dentista, não sentem dor de barriga, não têm sarampo.

- Nada disso.

- Não envelhecem. São sempre meninos.

- Decerto.

- Eu já presumia. Pois é, meu caro. Boa Terra. (RAMOS, 1977, p.115)

Enfim, tudo é perfeito, exatamente, como se espera em uma sociedade igualitária, distante de um Estado, cujos direitos de alguns são suprimidos em benefício de uma pequena parcela da população

\section{Considerações Finais}

Conforme observamos ao longo de nosso texto, é extremamente relevante trazer a lume as obras de Graciliano Ramos destinadas à criança e ao jovem, mostrando como elas fazem parte, sim, de seu projeto estético literário. Suas narrativas destinadas ao público infantil mantêm uma simetria com as narrativas destinadas aos adultos, visto que muitos de seus personagens possuem caraterísticas semelhantes, como a necessidade constante de buscar um espaço utópico, no qual são aceitos, respeitados e vivem em 
estado de igualdade com os outros sujeitos da sociedade. Vimos também que esse anseio por um espaço utópico advém de uma realidade inóspita e de, certa forma, de um Estado de Exceção, pois os personagens que são execrados, segregados e presos representam o desvio da norma e, em vista disso, sofrem um processo de apagamento social, porque tudo aquilo que eles são precisa ser anulado, seus direitos são retirados para que, assim, eles sejam conforme o que se dita como ser a norma, o correto, o desejo de um Estado opressor e injusto. A literatura de Ramos - dirigia a adultos, jovens ou crianças - constrói mundos ficcionais onde esses Estados de Exceção são questionados, possibilitando ao leito uma revisão dos conceitos de liberdade e de igualdade.

\section{Referências:}

AGAMBEN, Giorgio. Estado de exceção. Tradução de Iraci D. Poleti. São Paulo: Boitempo, 2004.

BACHELARD, Gaston. A poética do espaço. Tradução Antonio de Pádua Danesi. $2^{\circ}$ ed. São Paulo: Martins Fontes, 2008. (Tópicos).

BORGES, Lilliân. Nos rastros do sujeito: espacialidades, subjetivação e dessubjetivação em Memórias do Cárcere. Dissertação de mestrado. Universidade Federal de Uberlândia. Programa de Pós-graduação em Estudos Literários, 161f, 2017.

BULLYING. Dicionário online informal. 25 jan. 2017. Disponível em http://www.dicionarioinformal.com.br/significado/bullying/3728/. Acesso em 25 jan.2017.

CANDIDO, Antonio. Ficção e Confissão: ensaios sobre Graciliano Ramos. $4^{\circ} \mathrm{ed}$. Rio de Janeiro: Ouro sobre Azul, 2012.

FACÓ, Ruy. Graciliano Ramos, escritor do povo e militante do PC. In: Conversas. Organização Thiago Mio Salla, Ieda Lebensztayn. 1ªed. Rio de Janeiro: Record, 2014.

FOUCAULT, Michel. Outros espaços. In: Ditos e Escritos III: Estética: literatura e pintura, música e cinema. Organização e seleção de textos. Manoel Barros da Motta. Tradução Inês Autran Dourado Barbosa. $2^{\mathrm{a}} \mathrm{ed}$. Rio de Janeiro: Forense Universitária, 2006.

MOURÃO, Rui. Procura de Caminho. In: Alexandre e outros heróis. 55a ed. Rio de Janeiro: Record, 2011.

RAMOS FILHO, Ricardo. Graciliano na terra dos meninos pelados. In: Graciliano Ramos: muros sociais e aberturas artísticas. Organização de Benjamin Abdala Junior. $1^{\text {a }}$ ed. Rio de Janeiro: Record, 2017. 
RAMOS, Graciliano. Alexandre e outros heróis. Posfácio Osman Lins. Ilustrações Moraes. 14ª ed. Rio, São Paulo. Record, Martins, 1977.

RAMOS, Graciliano. Luciana. In: Insônia. Posfácio de Letícia Malard. $31^{\circ}$ ed. Ed. revisada. Rio de Janeiro: Record, 2013.

RAMOS, Graciliano. Angústia. Posfácio de Silviano Santiago. $69^{\circ}$ ed. Rio de Janeiro: Record, 2014.

RAMOS, Ricardo. Graciliano: retrato fragmentado. São Paulo: Globo, 2011. 